\title{
From Mathematics to Quantum Mechanics - On the Conceptual Unity of Cassirer's Philosophy of Science (1907 - 1937)
}

\section{Thomas Mormann}

2. Philosophy of Science as a Theory of Scientific Concepts 6

3. How Not to Understand Idealization and the Ideal Character of Scientific Knowledge 13

4. The Causality Principle and the Problem of Reality 20

5. On the Reception of DI 27

6. Cassirer - A Structural Realist avant la lettre?

$\begin{array}{ll}\text { References } & 38\end{array}$

Keywords: Neo-Kantianism, Structuralism, Empiricism, Realism, Idealization, Mathematics, Quantum Mechanics, Cassirer, Margenau, Ignorabimus.

\section{Abstract:}

1. Introduction. The two fundamental scientific revolutions that shaped the modern physics of the 20th century took place in Cassirer's lifetime; first Einstein's theory of relativity (Einstein 1905, 1915), and secondly quantum physics (Planck 1900, Heisenberg 1925, Schrödinger 1926). Cassirer reacted to both events with contributions that can claim, even today, the attention not only of philosophers of science but also of physicists who are interested in philosophical and historical reflections concerning their discipline. Cassirer's pertinent works in this respect are Zur Einsteinschen Relativitätstheorie (Cassirer 1921, 
henceforth ERT) and Determinismus und Indeterminismus in der modernen Physik (Cassirer 1937, henceforth DI). In these two works Cassirer attempts to come to terms philosophically with the just mentioned two characteristic revolutions of modern physics, relativity theory and quantum theory.

The following list shows a rough time-table of the most important "revolutionary" events in the evolution of physics in the first quarter of the 20th century and the publication dates of some of Cassirer's most important works in philosophy of science:

\begin{tabular}{|l|l|}
\hline \multicolumn{1}{|c|}{ Physics } & Cassirer's Philosophy of Science \\
\hline 1900 Planck's Law of Black Body Radiation & \\
\hline 1905 Special Theory of Relativity & 1907 Kant und die moderne Mathematik \\
\hline 1915 General Theory of Relativity & 1910 Substanzbegriff und Funktionsbegriff \\
\hline & 1921 Zur Einsteinschen Relativitätstheorie \\
\hline 1925 Heisenberg's Matrix Mechanics & $\begin{array}{l}\text { Formen I - III } \\
1926 \text { Schrödinger's Wave Mechanics }\end{array}$ \\
\hline & $\begin{array}{l}1937 \text { Determinismus und Indeterminismus in } \\
\text { der modernen Physik }\end{array}$ \\
\hline
\end{tabular}

Although Cassirer played an active role in the attempts to contribute a philosophical understanding of the most recent developments in physics, perhaps somewhat surprisingly during his whole career as a philosopher of science he saw no reason to abandon the basic convictions of his philosophy of science that he had developed in Substanzbegriff und Funktionsbegriff (Cassirer 1910, henceforth SF) on the basis of classical 19th century physics. On the contrary, in DI he put forward the thesis: 
The fundamental viewpoint, in accordance with which I have dealt with these problems [the philosophical problems posed by quantum physics], does not differ essentially from that of my Substance and Function. This viewpoint is, I believe, still justifiable. Indeed, I think I can now justify it better and formulate it more precisely on the basis of the developments in modern physics than I formerly could. (DI, xxiii)

To put it bluntly, in DI Cassirer was engaged in interpreting quantum mechanics in the same neo-Kantian frame that he used more than fifteen years earlier in ERT to make philosophical sense of Einstein's relativity theory. Even more, in DI he put forward the thesis that quantum mechanics provided a further proof of the relational character of the concepts of modern physics. This entailed that the relational (or functional) Ansatz of his philosophy of science first elaborated in SF - remained unaffected by the scientific revolutions of the 20th century. Taking into account the early programmatic paper Kant und die moderne Mathematik (1907, henceforth KMM) one may even go further and claim that from KMM (1907) onwards to SF (1910) and DI (1937) Cassirer's philosophy of science is characterized by a thoroughgoing conceptual continuity or even invariance. The aim of this paper is to make explicit this thesis by detailed textual comparisons. Moreover, I want to show that this invariance cannot be simply dismissed as a philosopher's excuse for not keeping up with the novel conceptual challenges of his time. More precisely I propose to read Cassirer's KMM, SF, ERT, and DI as integral parts of a comprehensive and coherent "idealist" philosophy of science of the early 20th century. In this interpretation, KMM plays the role of a programmatic overture where essential ideas and themes are already suggested in an early stage; SF may be seen as an 
execution of this program in the realm of classical physics, while ERT and DI may be taken as resumptions of the classical themes in the fields of modern physics. ${ }^{1}$

As I want to argue in detail in the following, in particular the connections between KMM and SF on the one hand, and DI on the other, are surprisingly close. This shows that Cassirer's functional or relational account can be applied in a fruitful way to classical and modern physics. It is therefore a fundamental misunderstanding of Cassirer's philosophy of science to read it as an epigonal attempt to immunize an obsolete neo-Kantian account in such a way that is confirmed by just any new scientific achievement. Rather, the insight in the relational character of scientific concepts should be considered as a lasting contribution of Cassirer to philosophy of science. This does not mean, of course, that one has to subscribe to all details of his approach.

The outline of the paper is as follows. To set the stage, in section 2 we briefly recall the basic ideas of Cassirer's philosophy of science as expounded programmatically in his early paper $\mathrm{KMM}$ and presented in mature form in SF. For him, the relational character of physical concepts had become visible already in classical physics, the formation of radically relational concepts in quantum mechanics was only a confirmation and further clarification of this tendency.

\footnotetext{
${ }^{1}$ For reasons of space I deal with ERT only briefly. The point I want to make is that Cassirer's relational philosophy of science covers classical and non-classical physics. To argue for this claim it may suffice to deal with $\mathrm{DI}$ and the issue of quantum mechanics.

In matters of philosophy of science (and philosophy of mathematics) Cassirer's opus magnum Philosophy of Symbolic Forms (Cassirer 1923 - 1929, henceforth PSF) follows SF rather closely. The essential ideas of SF are rehearsed in PSF III, sometimes in extensive quotations. Although ERT had already appeared in 1921, in PSF III Einstein's theories are mentioned only in passing. This is evidence that Cassirer saw no need to alter the fundamentals of his philosophy of science, as he had presented them in SF in the light of the theory of relativity. In other words, he interpreted the "new relativistic physics" as a confirmation of his functional account. There is, however, one point in PSF III which goes beyond SF. On the last pages of PSF III he deals with the concept of field that first emerged in the context of Maxwell's theory of electromagnetic fields. Cassirer conceives fields as a striking example for the growing tendency in modernity to replace "thing-concepts" with "relation-concepts": "The reality that we designate as a field is no longer a complex of physical things, but an expression for an aggregate of physical relations." (PSF III, 465). Later, in DI he dealt with fields in more detail in the context of quantum theory.

When writing PSF Cassirer was already acquainted with the "old" quantum theory. He mentions briefly and in passing through the works of Bohr, Planck, and Sommerfeld (cf. PSF III (445, 446, 475n). Heisenberg and Schrödinger are not mentioned at all.
} 
In section 3, How Not to Understand Idealization and the Ideal Character of Scientific Knowledge, we deal with Cassirer's refutation of certain misconceptions that threatened a correct understanding of the roles of idealization and ideal concepts in science. In SF Cassirer critizised the account of the mathematician Paul du Bois-Reymond who claimed to have shown in his Allgemeine Functionentheorie (Paul du Bois-Reymond 1882) that the concepts of idealization and limit necessarily possessed certain aporetic features which directly threatened the very feasibility of Cassirer's "critical idealist" approach of SF that basically relied on "limiting concepts" (Grenzbegriffe).

Almost 30 years later, in DI, Cassirer took sides again against the account of idealization that the brothers du Bois-Reymond had propagated since the last decades of the 19th century. In DI Cassirer primarily attacked Emil du Bois-Reymond's account of causality that the latter had derived from the idealized model of science based on the thought-experiment of the almost omniscient Laplacian demon. Cassirer argued that du Bois-Reymond's arguments rested on a confused concept of causality that had been rendered obsolete by modern science.

In section 4 The Principle of Causality and the Problem of Reality we deal with Cassirer's conception of causality as presented in DI. According to general wisdom, the most important revolutionary feature of quantum theory was that it forced us to abandon the classical concept of causation. Cassirer disagreed. According to him, causality was a relation within the realm of conceptual objects and not between of objects in nature. In modern science causality has to be attributed to a model which the science constructs out of concepts. It does not directly refer to "reality“. Hence quantum theory does not urge us so much to give up the concept of causality but to rethink the concepts of object and objectivity in a way that takes into account in a more thoroughgoing way the relational character of the concepts of exact empirical sciences. Section 5 deals with the complex reception that DI had in 20th century philosophy of science up to the present. On the basis of $\mathrm{DI}$, in some philosophical quarters, Cassirer is considered as a forerunner of contemporary structural 
realism (in the philosophy of quantum mechanics and beyond). This topic is discussed in detail in section 6. It is argued that recruiting Cassirer posthumously for the camp of structural realism does not do full justice to his approach. Rather, he probably would have felt more at home with a kind of structural empiricism (cf. van Fraassen 2006, 2008), or so I want to argue.

2. Philosophy of Science as a Theory of Scientific Concepts. "The investigations contained in this volume were first prompted by studies in the philosophy of mathematics." (SF, iii). This is the very first sentence of SF. This assertion should be taken seriously. Cassirer's philosophy of science is inspired more profoundly by mathematics than any other philosophy of science of the 19th and 20th century.

The most characteristic feature of Cassirer's philosophy of science is how the relation between mathematics and physics is conceptualized, or, more generally, the relation of mathematics and the (mature) empirical sciences. As he pointed out in KMM, philosophy of science has to concentrate neither on mathematics, as a science of ideal objects, nor on physics, as a science of empirical objects, but rather:

If one is allowed to express the relation between philosophy and science in a blunt and paradoxical way, one may say: The eye of philosophy must be directed neither on mathematics nor on physics; it is to be directed solely on the connection of the two realms. (KMM, 44)

According to Cassirer, the basic task of philosophy of science is to look for the common root from which both physical and mathematical concepts spring. This common root is identified as the activity of constructing ideal concepts or limit concepts (Grenzbegriffe) that are 
necessary to order and unify the wealth of experiences. The main organon for this endeavor is the new relational logic inaugurated by Frege, Peano, Russell, and others. This logic had emerged from the evolution of mathematics itself. For Cassirer, being a member of the Marburg school of neo-Kantianism, this was no coincidence. Rather, it confirmed the basic neo-Kantian thesis that the history of science plays an eminent role for the philosophy of science. It led the critical idealism of the Marburg school to a genetic epistemology that regarded the process of the conceptual evolution of science as essential, not so much the certainty and truth of the temporary results of science.

Cassirer's philosophy of science treated mathematics and physics as a conceptual unity. More precisely, his approach was based on the general "idealist" thesis

that the same foundational syntheses on which logic and mathematics rest also govern the scientific construction of experiential knowledge, that only they enable us to speak of a strict, lawful ordering among appearances and therewith of their objective meaning, only then the true justification of the principles is attained (KMM, 44):

Thus, to put it bluntly, according to Cassirer, mathematical knowledge and physical knowledge are basically of the same kind. Both are characterized by the introduction of "ideal elements" which in both areas play essentially the same role. This thesis may be dubbed the "sameness thesis". It may be considered as an invariant feature of his philosophy of science from the beginning to the end. For the first time, Cassirer put forward the sameness thesis in KMM $(1907,44)$, with only slight simplification one may read the whole of SF as an ample elaboration of this thesis. Eventually, in DI it is argued that one may even go further and claim that from the sameness thesis is confirmed and clarified in light of the new revolutionary achievements of quantum physics. For instance, when resuming the achievements of $\mathrm{DI}$ in the penultimate chapter of this work, Cassirer contended that quantum 
mechanics has brought to the fore once again the fundamental similarity between mathematical and physical concepts, in particular, the conceptual similarity between geometrical points and material points, namely, that both are implicitly constituted as aggregates of relations (cf. (DI, 195)). In other words, mathematics was not a "logical oddity" or a "logical exception" (logisches Unikum) (SF, 230)2 but an integral component of the philosophy of science as a whole. More specifically, the formation of mathematical concepts was to be considered as the prototype of the formation of scientific concepts in general.

What "Critical Idealism" seeks and what it must demand is a logic of objective knowledge. Only when we have understood that the same foundational syntheses on which logic and mathematics rest also govern the scientific construction of experiential knowledge, that only they enable us to speak of a strict, lawful ordering among appearances and therewith of their objective meaning: only then the true justification of the principles is attained. (KMM, 44)

Although the principles of the processes of the formation in mathematics and physics are basically the same, they are not identical. Rather, the formation of mathematical concepts may be conceived of as a "finite" version of the more open formation of physical concepts: In contrast to the mathematical concept, however, in empirical science the characteristic difference emerges that the construction which within mathematics arrives at a fixed end, remains in principle incompletable within experience.

It is important to note that for Cassirer "ideal gases", "perfect fluids" and their (idealized) relatives are not just approximated by the more or less ideal gases and the more or less perfect fluids "to be found in nature". Rather, idealizing concepts such as ideal gases or

\footnotetext{
2 The expression "logisches Unikum" is difficult to translate: Taking into account the Latin origin of "Unikum", it may be translated simply as "something unique". "Being unique" in the sense of "Unikum" carries with it, however, the connotation of "being odd" or "being an exception". Hence, in a more pronounced manner "logisches Unikum" may be rendered "logical oddity" or "logical exception".
} 
perfect fluids play an epistemological role essentially different from their non-ideal counterparts. Ideal concepts provide conceptual perspectives that allow the formulation of general relational laws and thereby they help make sense of reality as a manifold of experiences. The indispensability of idealization for scientific knowledge entails that the factual and theoretical components of scientific knowledge cannot be neatly separated. In a scientific theory, "real" and "non-real" components are inextricably interwoven:

The relation between the theoretical and factual elements at the basis of physics is a ... peculiar interweaving and mutual interpenetration of the theoretical and the factual, that prevails in the actual structure of science and calls for clearer expression logically of the relation between principle and fact. (SF, 130)

This entails that no single concept of physics is confronted with reality but a whole system of concepts:

We do not have physical concepts and physical facts in pure separation, so that we could select a member of the first sphere and inquire whether it possessed a copy in the second; but we possess the "facts" only by virtue of the totality of concepts, just as, on the other hand, we conceive the concepts only with reference to the totality of possible experience. (SF, 147)

Surely, this holism is not breaking news for philosophy of science in the second decade of 21 th century, but for a fair assessment of the novelty of this claim one should take into account that is was put forward in $1910 .{ }^{3}$ Moreover, quite recently, this holism plays an important role in the relations between Cassirer and contemporary "ontological structural realism“ (OSR) (see section 6).

\footnotetext{
${ }^{3}$ In DI, Cassirer put great emphasis on the fact that his holism is, so to speak, an articulated holism that takes into account the different kinds of physical statements, statements of results of measurement, of laws, and of principles. This articulation is not to be thought, however, as a hierarchical structure: "If we choose a spatial analogy for the structure of physics, we must not liken this structure to a pyramid ... but to the "well-rounded sphere" with which Parmenides compared his universe..." (DI, 35).
} 
In line with the historicist orientation of Neo-Kantianism, conceptualizing the philosophy of science as a theory of the formation of scientific concepts entails that it has to study the evolution of scientific concepts in the course of their historical development. From the time of his earliest publications, Cassirer endorsed the thesis that for the development of modern mathematics the concept of function was of the outmost importance (cf. Cassirer (1902), KMM, SF, PSFIII). For him the concept of function encapsulated the essence of modern scientific thought. The conceptual evolution of modern science could be described as the emergence of the functional character of scientific concepts.

In light of the methods and the results of modern structural mathematics, it is not too difficult to accept the thesis of the relational character of mathematical concepts. According to common wisdom, all mathematical objects may be conceived as relational structures. Less plausible is the stronger thesis that this also holds for the concepts of empirical science. Cassirer is well aware of the fact that this step from mathematics to physics is the most difficult obstacle that his theory of the formation of scientific concepts has to overcome. In chapter 4, the largest chapter of SF, he tackled this challenge. After having argued in the preceding chapters for the relational character of mathematics, in this central chapter of SF Cassirer attempted to generalize his relational theory of concepts of mathematics to a comprehensive theory of the formation of concepts of physics and chemistry:

The exact scientific concepts only continue an intellectual process already effective in pure mathematical knowledge. ... The theoretical concepts of natural science are in no sense merely purified and idealized word-meanings; ... They always contain reference to an exact serial principle, that enables us to connect the manifold of intuition in a definite way, and to run through it according to a prescribed law. (SF, 223) 
It is one of the basic tenets of the Marburg Neo-Kantian philosophy of science that this "intellectual process" of scientific concept formation has no end. Scientific concepts in the understanding of the Marburg school were always preliminary concepts, to be replaced by better ones in the course of the evolution of science. Or, in the words of Paul Natorp, science was a fact in becoming (Werdefaktum). Hence for Cassirer, the dynamical character of scientific concepts became most clearly visible in the formation of the concepts of empirical science (SF, 113).

More precisely, Cassirer contends that the conceptual evolution of the empirical sciences had the tendency that the "thing-concepts", characteristic of the more primitive stages of a science, are transformed into relational or functional concepts (cf. SF, 225). Thus it is an important task of the philosophy of science to render the relationalization of this process explicit. As a paradigmatic example for this process he discusses in SF the conceptual evolution of chemistry (cf. SF, chapter IV):

[I]f the chemical concept of a certain body is given by its constitution-formula, in which it is grasped as a particular material in its characteristic structure, it is at the same time brought under the various chemical "types", and is thus set in a definite relation to the totality of remaining bodies (SF, 224).

A paradigmatic example of a relational concept in physics was for Cassirer the concept of energy. The utility of the concept of energy is not to describe any new class of objects, alongside the already known physical objects such as light and heat, electricity and magnetism. Rather, the concept of energy signifies an objective lawful correlation, in which all these "objects" stand. The meaning of the concept of energy resides in the equations that it establishes among different kinds of events and processes. Energy in the sense of modern science is not an object in the traditional sense, but a unifying perspective that sheds light 
on a manifold of experiences. This is rendered most evident by the functional identity of potential and kinetic energy through which states are identified with temporal processes:

The two [moments of kinetic and potential energy] are "the same" not because they share any objective property, but because they occur as members of the same causal equation, and thus can be substituted for each other from the standpoint of pure magnitude (SF, 199)

Theoretical concepts such as energy cannot be understood as the conceptual counterpart of something empirical out there. Rather, it is to be understood as an order-generating principle. In this respect it resembles the notion of number by which we make the sensuous manifold unitary and uniform in conception (cf. SF, 189)). In contrast to the concept of number, the concept of energy is a genuine concept of the empirical sciences. Hence, since "number" and "energy" both served as order-generating principles in essentially the same manner, this was considered as another argument in favor of the Marburg thesis that mathematics and mathematized empirical sciences followed the same rules of one and the same transcendental logic This endeavor is taken up again in a more radical vein on the basis of non-classical examples from quantum mechanics in DI.

The thesis that mathematical concepts and concepts of exact empirical sciences are intimately related lies at the heart of Cassirer theory of the formation of scientific concepts. It may explain the wide spectrum of his philosophy of science ranging from philosophy of mathematics to philosophy of quantum physics including philosophy of chemistry and touching even philosophy of biology. This variety of concepts did not simply amount to a juxtaposition of concepts of unrelated disciplines, rather, from Cassirer's point of view it exhibited a conceptual unity that is hardly visible from the perspective of philosophical mainstream. 
According to Cassirer concepts should be characterized functionally, i.e., by what they achieved for the evolution of scientific knowledge. From this perspective, mathematical concepts as well as theoretical concepts of physics have similar roles:

Concepts do not gain their truth by being copies of realities presented in themselves, but by expressing ideal orders by which the connection of experiences is established and guaranteed. The "realities," which physics affirms, have no meaning beyond that of being ordering concepts. They are not grounded by pointing out a particular sensuous being, that "corresponds" to them, but by being recognized as the instruments of strict connections and thus of thoroughgoing relative determinateness of the "given" (SF, 319).

As we shall see later (cf. section 6), this instrumentalist interpretation of the role of theoretical concepts brings Cassirer's account in the conceptual neighborhood of van Fraassen's project of a "structuralist empiricism" (van Fraassen (2006, 2008), or so I want to argue.

\section{How Not to Understand Idealization and the Ideal Character of Scientific Knowledge.}

Cassirer's emphasis on the importance of idealization for scientific knowledge evidences that for him idealization was not an issue that should be taken lightly by the philosophy of science. Indeed throughout his career as a philosopher of science he was committed to fighting against conceptions of idealization that, as he was convinced, would lead us astray in our effort to understand the complex "fact of science" and the various roles that idealizations play in it.

Throughout his life Cassirer was engaged in the task of elaborating a "realist" concept of idealization that did justice to the way of how idealization "really" worked in "real" science. A 
part of this endeavor was to criticize the flaws and shortcomings of the attempts of other philosophers to cope with this problem. A preferred target of Cassirer's criticisms were the proposals that the brothers Paul and Emil du Bois-Reymond had put forward in the last decades of the 19th century (cf. Emil du Bois-Reymond (1872), Paul du Bois-Reymond (1882, 1890)). Cassirer extensively dealt with the theses of the du Bois-Reymonds in SF, PSFIII, and DI. This may be taken as evidence that he considered their theses as important, although philosophically mistaken claims.

The common point of departure for Cassirer's SF and Paul du Bois-Reymond's Die Allgemeine Funktionentheorie (1882) was the fact that the theoretical laws of modern science do not directly refer to perceptual data. Rather, the scientific image of the world is grounded on a wealth of idealizations in which the indefinite empirical data are replaced by strict conceptual limits. The ways of Cassirer and du Bois-Reymond parted when it came to the problem of determining the "ontological status" of these idealizations or limit concepts.

According to du Bois-Reymond there existed two different ways to tackle the problems posed by such limiting concepts (cf. du Bois-Reymond (1882, 3, 78 - 176)). The first he called the way of idealism, the second the way of empirism. Du Bois-Reymond characterized the idealist approach by the assumption that conceptual limits, which are required by our cognizing activity, exist in the same way as the objects of our perceptions. On the other hand, du Bois-Reymond's "empirist" only recognized what can be perceived. This stance, however, is too austere to adequately describe the knowledge of modern science because it depends on the assumption that ideal objects such as the absolutely rigid body, the atom, or the force of a distance do exist in the same way as particular data exist. On the other hand, the idealist's candid claims of the existence of ideal objects seem to be extravagant and unjustifiable, because the existence of these ideal entities clearly transcends the accessible world of sensuous appearances. In sum, du Bois-Reymond's idealist as well as his empirist seem to be trapped in an aporetic dilemma. 
Contemporary philosophers with empiricist inclinations use to express this dilemma by saying that the idealizing scientific concepts are "lying" or "falsifying" reality but nevertheless are needed for the scientific endeavor. Other scholars, with less empiricist qualms assert that the idealized theories of science do not apply to the actual world but to some mysterious 'ideal worlds'. An extreme example is provided by Leszek Nowak's "(supra-)realism" (cf. Nowak(1995)). Nowak argues for a strong realism with respect to ideal objects:

[A]ll our idealizational "constructs" are not constructs but true descriptions of some existing ideal worlds. ... As it were, we are unable to theoretically invent something which would not hold nowhere, in no world. (Nowak 1995, 236)

Our thinking consists only in finding some thing that holds somewhere, in some world. And the idealizational thinking straightforwardly falls under this rule. (ibid., 238)

According to Nowak, we are able to perceive "somehow" facts of ideal worlds in the same way as we are able to perceive facts in the real world. Cassirer vigorously protested against du Bois-Reymond's allegedly unescapable dilemma. both interpretations of the role of idealizations. He neither accepted the stance of du Bois-Reymond's conceptually consumptive "empirism" that accepted idealizations only with bad conscience as (perhaps) necessary lies, nor was he prepared to buy into an overstated "idealism" that indulged in the existence of countless phantastic ideal worlds populated by more or less phantastic ideal objects. Rather, rightly understood,

[The] ideal concepts of natural science affirm nothing regarding a new realm of separate absolute objects, but they only want to establish the inevitable, logical lines of direction, by which alone complete orientation is gained within the manifold of the phenomena. They only go beyond the given, in order to grasp 
more sharply the systematic structural relations of the given. (SF, 128)

Cassirer would have considered Nowak's account of idealization as a wildly overstated idealism put forward by an extravagant "idealist à la du Bois-Reymond" who has not understood the complex relation between the real and the ideal. For Cassirer, the "worlds" where we find ideal gases, ideal planes, point masses and so on, are worlds only in a highly metaphorical sense. Moreover, these "ideal worlds" do not have much to do with the processes of idealization that the scientists carry out to come to terms with the real world. In these processes the indefinite data of sensations are supplanted by their strict conceptual limits. Nevertheless the assertion of the objective validity of these processes should not be confused with the assertion of the existence of a new class of objects, to say nothing about the existence of a new class of worlds.

According to Cassirer the fundamental flaw of du Bois-Reymond's idealist consists in reifying the ideal. The ideal concepts, which real science employs for the logical interpretation and mastery of the manifold of sensations, are transformed into mysterious realities behind, and independent, of the phenomena. This is paradigmatically exemplified by Nowak's "suprarealism". This species of an idealist, Cassirer remarks, "has permitted his conception (of the ideal) to be perverted by his opponent the "empiricist"“.

Cassirer offered the following proposal of a reconciliation between the two extreme standpoints: (i) The empiricist should admit the necessity of idealizing if he wants to come to terms with the real world. Without introducing certain appropirate idealizations science is simply not possible:

This reduction of the manifold and ceaselessly changing material of perception to ultimate constant relations must be granted by even the most radical "empiricism." For the assumption of this fundamental relation is all that remains 
for empiricism of the concept of the "object," and thus of the conception of nature. (SF, 260)

The necessity of idealizing does not entail, however, the recognition of ideal objects as objects of "real" ideal worlds. This is to say, in order to achieve a peaceful coexistence with the empiricist the idealist has to recognize only the irreality of ideal concepts and being content with the objectivity of the activity of idealizing.

In virtually all his important contributions to the philosophy of science Cassirer argued that "critical idealism" escaped du Bois-Reymond's dilemma according to which one had to choose between an anorexic empiricism and an extravagant idealism. He contended that his "critical idealism" put forward an adequate understanding of what idealization really meant and what its real function was for modern science. In brief, the critical idealist approach showed contra du Bois-Reymond - that it was possible to describe the idealizing practice of real science in a plausible and non-aporetic way.

Ideal concepts such as point-masses, frictionless planes and so on are not the only ingredients of scientific knowledge for which idealization plays essential role. Idealization also plays a role in the philosophy of science proper, namely, in the highly idealized models of science that philosophers of science employ in their speculations about science. These models may be characterized as global idealizations. In contrast, ideal concepts such as point-masses, perfect fluids etc. are local idealizations - they affect only relatively small areas of scientific knowledge.

Pertinent examples of such "global idealizations" are the various accounts of an "ideal physics“, models of ideal neuroscience and psychology that ignore the embarrassing but allegedly inessential shortcomings and deficiencies that at present still hamper these sciences. One may distinguish between negative and positive global idealizations. Negative idealizations are concerned with some allegedly "absolute" limitations of science according to which science will never be able to answer certain questions or solve certain problems. Which 
problems science allegedly will never solve varies, of course, widely with time and ideological background of those who put forward such a thesis.

Positive global idealizations claim that for understanding the essence of science it is expedient to ignore certain inessential limitations of present day science, for example our limited capacities of calculations, limited precision of measurements etc. which certainly affect the results of present day science but can be ignored sub specie aeternitatis for an ideal science. Perhaps the most important and most influential example of such a global idealization that Cassirer's critical idealism was confronted with was the model of scientific knowledge encapsulated in the metaphor of the Laplace's demon and his immense physical knowledge concerning the whole past and future of the world. In the last decades of the 19th century the prominent physiologist and philosopher Emil du Bois-Reymond (and his brother Paul du Bois-Reymond) used this model of an ideal physics to argue for the existence of some unsurmountable limits ("Ignoramus et ignorabimus") for human scientific knowledge. The negative part of their argument is simple: Clearly, the demon's physical knowledge is at least as comprehensive and profound as that which mankind can ever hope to achieve. Thus, if there are problems that the demon is unable to solve then these are unsolvable for mankind a fortiori. The positive part of du Bois-Reymond's argument is less trivial but philosophically more interesting. Du Bois-Reymond takes it for granted that the demon's physical knowledge can be considered as a faithful, although idealized model of human physical knowledge.

Over the decades, du Bois-Reymond's thesis had an immense repercussion in the German academia and beyond. ${ }^{4}$ In DI, Cassirer vigorously attacked du Bois-Reymond's Laplacian model of an ideal science arguing that it lead to a confused and obsolete conception of causality. In particular, he critizised du Bois-Reymond's "Ignorabimus"-thesis as an artifact of bad

\footnotetext{
${ }^{4}$ Still in 1930 David Hilbert felt called to contradict du Bois-Reymond at the meeting of the German Mathematical Society in Königsberg: "We must not believe those, who today, with philosophical bearing and deliberative tone, prophesy the fall of culture and accept the ignorabimus. For us there is no ignorabimus, and in my opinion none whatever in natural science. In opposition to the foolish ignorabimus our slogan shall be: Wir müssen wissen - wir werden wissen! In different ways, logical empiricists such as Carnap and Frank argued against du Bois-Reymond's ignorabimus (cf. Carnap (1928), Frank 1949).
} 
metaphysics and approvingly quoted Richard von Mises (cf. (DI, 9)) according to whom du Bois-Reymond's “ignorabimus" "has no other significance for us than the sober kowledge that the mathematician has of the impossibility of squaring the circle and of other similar problems... ." For Cassirer, the idea of an ideal science, suggested by Laplace's demon was an idealization that lead us astray. Rather, faithful to the Marburg maxim of learning from the history of science what science is, he proposed to look at the most promising scientific theory then available for clues about how an ideal science would look. For Cassirer, quantum mechanics was a compelling argument that we have to formulate the ideal of science in a different way:

"We must formulate the ideal and principle of scientific knowledge differently and from a new point of view if the principle is to be logically coherent and empirically useful, applicable to the procedure of "actual" physics and its formation of concepts. (DI, 10)

$\cdots$

The causal problem must be grasped as a problem of "discursive,", not of "intuitive," understanding, of a finite, not of an infinite intellect. If this finite intellect is limited, this limtation implies by no means a merely negative, but rather a positive, characterization. ... It rather delimits the domain in which alone our thinking and knowing find fulfillment, in which alone they win concrete significance. (DI, 23)

In other words, acknowledging the necessity of idealizing does not amount to adopting a "God's eye" point of view. On the contrary, idealization in science is justified by an argument which draws its strength from another, quite different source, namely, the insight into the

\footnotetext{
${ }^{5}$ It may be interesting to note that the young Carnap had no qualms in applying Laplace's model of ideal scientific knowledge, see his Die Aufgabe der Physik und das Prinzip der Einfachstheit (Carnap 1923). In contrast, Carnap's fellow empiricist Neurath vigorously rejected the Laplace's model of scientific knowledge ("The system is the great scientific lie"). Somewhat ironically then, Cassirer, aiming at a realist model of science "as it is practiced by scientists", sided with Neurath with respect to the issue of idealization. Carnap was never very much interested in the task of overcoming the possibly distorting features of the philosophically and logically overidealized models of science that philosophers are prone to deal with instead of "real" science. On the other hand, all logical empiricists agreed that du Bois-Reymond's Ignorabimus, i.e., his forever unsolvable "world riddles" were meta-physical pseudoproblems.
} 
finiteness of the human mind and its conceptual achievements. In other words, the necessity of idealization in human "discursive" science is the key ingredient for doing justice to the essential aspect of its finiteness. Laplace's model of an ideal science freed of all limitations that beset real science, seriously misrepresents it. Idealization is a central issue for every kind of philosophy of science that aims to understand "real" science and is not content with a metaphysical surrogate inspired not by science but rather by some sort science fiction. As will be explained in detail, Laplace's model destroys an essential feature of any finite human science, namely, its non-intuitive discursive character of science. ${ }^{6}$

4. The Causality Principle and the Problem of Reality. The starting point for Cassirer's account of causality is the assumption that causality is to be found not in nature but is to be conceived as an ingredient of our theories about nature. Or, as Victor Lenzen put it:

Causality is a relation within the realm of conceptual objects. The relation of cause and effect refers to conceptual events regardless of the relation of the latter to reality. ... In the sophisticated age of science causality must be attributed to a model which the scientist constructs out of concepts. ((Lenzen quoted by Margenau in (DI, xii))

Indeed, Cassirer explicitly contended that in light of modern science it is no longer possible to maintain that causal relations have empirical content (cf. (DI, 60)). Nevertheless, they are not superfluous. Rather, the principle of causality is a methodological principle. Evidently, this thesis is in need of further explication. Causality is concerned with all domains of physical

\footnotetext{
${ }^{6}$ In their opposition to the Laplacian model of science again we find Cassirer and Neurath on the same side. They expressed their convictions, of course, in quite different ways. While for Neurath the Laplacian system was "the great scientific lie“, Cassirer characterized Laplace's model taken as the limiting point to which real science would converge, as a deceiving focus imaginarius (cf. (DI, 24)).
} 
knowledge and all aspects of scientific knowledge, but not in the same kind. In order to understand how it works it is necessary to investigate in some detail the structure of physical knowledge. For this purpose Cassirer distinguished between three types of physical statements:

- Statements of results of measurements

- Statements of laws

- Statements of principles

We may say that statements of results of measurements are individual, statements of law are general, and statements of principles are universal (cf. (DI, 54)). Cassirer insists that these three types of statements are statements of different types. There is no "continuous" path from one level to the other, rather, what is required, is a "jump" (ibid.).

Statements of the results of measurements are the first step in the transition from the realm of "given" to the realm of scientific knowledge, or, in other words "from the world of sense to the world of physics" (DI, 31). How this transition from "percepts" to "concepts" is to be thought has been explained in sufficient detail in SF (The Concepts of Natural Science (Chapter IV)) and therefore need not be repeated in DI. The essential point of this theory of the formation of physical concepts is that the concepts of science cannot be understood simply as "copies“ or "abbreviations" of sensuous percepts but as constructions.7 In the following problems of the formation of physical concepts are left aside. DI will be essentially dealing not with questions concerning physical concepts but with questions concerning physical statements.

With respect to statements of measurement results, the first thing one observes is that the experimental observation in physics and other sciences has resulted in an immense

\footnotetext{
7 As more recent literature on the issue of the formation of physical concepts Cassirer recommends Carnap's Physikalische Begriffsbildung (Carnap 1926) and Hermann Weyls Philosophie der Mathematik und der Naturwissenschaft (Weyl 1927).
} 
extensional enrichment of our knowledge. Thus, it seems natural to assume that the importance of all our physical measuring insturments resides in the fact that they imporve the capacities of our natural sense organs. understand the importance of all our physical measuring instruments as their improvement of the capacities of our natural sense organs. This aspect of physical measurement is particularly visible in the case of visual perception. In this realm, microscopes, telescopes and other apparatuses appear simply to be devices that help overcome the contingent restrictions of our sense organs. This is, however, only one aspect of the use of instruments. At least as important is another, complementary aspect of physical experimentation:

For over against the broadening of our world picture, ... there comes about also a highly significant concentration. ... To the growing extensive range of knowledge there corresponds an ever stronger intensive penetration and mastery. (DI, 33)

Shaped by a basic conviction of Marburg Neo-Kantianism, Cassirer claims that these two tendencies - extension vs. concentration - are not in perfect equilibrium but the latter dominates the former. That is to say the history of physical knowledge is characterized by a tendency toward concentration and condensation as its organizing principle. This feature shows up in the formation of all physical concepts and judgments, be they statement of results of measurements, of laws, or of principles (cf. (DI, 34)).

In other words, there is a kind of dialectic between the extension and the condensation of scientific knowledge. This dialectic has a direction in so far as the tendency of concentration and unification is dominant. It takes place on all three levels of physical knowledge, beginning already on the level of measurement statement, and continuing in specific ways on the levels of statements of laws and of principles. The driving force in this dialectical evolution of scientific knowledge lies on the side of condensation, i.e., according to the Neo-Kantian perspective on the evolution of scientific knowledge the primary feature of this evolution is the ever-growing condensation und conceptual deepening of scientific knowledge. 
Statements of laws lead to further condensation and extension of scientific knowledge. Already in SF Cassirer had discussed as pertinent examples mathematical, physical, and chemical formulas (cf. (SF, chapter IV)). ${ }^{8}$ In DI he emphasizes that the transition from a particular case - expressed as a statement of the result of a measurement - to a statement of a law should not be conceived of as a merely extensional generalization but as a transition to another type of physical knowledge. Analogously, the transition from the level of statements of laws to the level of statements of principles is to be conceived of not as a "continuous" process of expansion, but as a discontinuous jump, i.e., as a metábasis eis allo génos (cf. (DI, 42)).

The distinction between „laws“ and „principles“ seems new. In SF Cassirer had not yet distin guished between laws and principles, rather, the two types of physical judgments laws were lumped together. In DI he clearly distinguished between the two levels, probably in the order to pave the way for the elucidation for the „principle of all principles“, namely, the principle of causality. Laws have empirical content, principles tend to be empirically empty. They are not themselves laws, but rules for seeking and finding laws (cf. (DI, 52)). The higher one ascends in the hierarchy of scientific propositions, the harder it becomes to distinguish between these propositions and the summit of the hierarchy, the principle of causality. (DI, 55) Cassirer treats in detail the historical evolution of the principle of least action and the principle of the conservation of energy (cf. (DI, 48ff)).

In order to understand the principle of causality as the highest principle of all principles it is expedient to recall the general characterization of the role of principles that Cassirer gave above: „Principles are ... rules for seeking and finding laws.“ This general characterization leads to a principle of causality tailor-made for the needs of method-centered Marburg NeoKantianism (cf. (DI, 60)):

\footnotetext{
${ }^{8}$ In this respect, grist for Cassirer's mill would have been Wigner's well-known dictum of „the unreasonable effectiveness of mathematics in the natural sciences". Instead of Wigner's "unreasonable effectiveness" Cassirer spoke of „the indwelling „sagacity“ (Spürkraft) of formulas, which he considered as,$\ldots$ one of the most remarkable and fascinating problems in the epistemology of science." (DI, 39).
} 
The principle of causality is not a new insight concerning content, but solely one concerning method. ${ }^{9}$ It is a postulate of empirical thought that specifies that the evolution of scientific knowledge can and should go on without limitation. The prinicple assumes that phenomena of nature do not withstand in principle the possibility of being ordered by science. The causal principle is a principle sui generis insofar as it is a statement about measurements, laws, and principles. It says that all these can be so related and combined with one another that from this combination there results a system of physical knowledge and not a mere aggregate of isolated observations.

The transcendental character of principle of causality entails that philosophy of science can never treat this issue in isolation. Rather, what is understood by causality always depends on certain assumptions concerning the nature of the objects of science and the concept of physical "reality" that is presupposed. For the case of quantum mechanics this means that the allegedly grave crisis of the concept of causality by that theory suggests a new understanding of the concept of the physical object, and, more globally, of the concept of physical reality. Indeed, Cassirer put forward the following radical thesis:

The essential problems posed by quantum mechanics for epistemology ... deal primarily not with the category of cause and effect but with the category of thing and attribute, of substance and accident. It appears that we must here carry through a more far-reaching transformation and relearn much more radically than we had to in the case of the causal concept. (DI, 188)

\footnotetext{
9 Similarly Thomas Nagel: According to him the principle of causality is a methodological rule of heuristic value which „bids us to analyze physical processes in such a way that their evolution can be shown to be independent of the particular times and places at which those processes occur." Nagel insists the principle of causality is a maxim for inquiry rather than a statement with definite empirical content (Nagel 1961, 320) with reference to DI. In Frank (1932) one finds similar contentions.
} 
According to the classical criterion of the real, to which virtually all pre-quantum epistemologies subscribe, something is real only if it is temporally and spatially completely determined. According to the Critique of Pure Reason:

Every thing ... is subject to the principle of complete determination, according to which if all the possible predicates of things be taken with their contradictory opposites, then one of each pair of contradictory opposites must belong to it. (Kant 1933 (1787), A572, B600)

In the light of quantum mechanics, this principle of complete determination of every „real“ thing had to be given up. Quantum theory requires a new concept of physical state that is incompatible with that of classical physics (cf. (DI, 190)). Insofar as „empiricist" and „rationalist“ philosophers of science alike subscribed to a Kantian strict correspondencebound between complete determination and reality they clash with the new results of non-classical physics. In DI Cassirer mentions Natorp's Die logischen Grundlagen der exakten Wissenschaften (Natorp 1910) and Schlick's Allgemeine Erkenntnislehre (Schlick $1925^{2}$ ) as two contemporary examples whose criteria of reality are seriously affected (or even rendered obsolete) by the new results of quantum mechanics (cf. (DI, 189f).

This is not the case for "critical idealism“, Cassirer argues. The epistemological framework of "critical idealism" is sufficiently flexible to cope with the new challenge that quantum mechanics represents. According to Cassirer, quantum mechanics, or, more precisely, the uncertainty relations of quantum mechanics teaches us „the impossibility of drawing a sharp line between nature itself and our knowledge of nature. ... Nothing that is not ... for physical knowledge in any sense, is any longer in „itself“ in nature.“ (DI, 194). Cassirer intends to render plausible this breakdown of the Aristotelian difference between „for us" and „in itself“ by invoking the close affinity between physical and mathematical concepts put forward already in KMM and explicated later in SF and other works. According to him, one of most 
important advances of modern mathematics was the insight that mathematical objects such as points, lines, and curves

no longer have a firmly determined existence or a definite significance ascribed to them independently of their mutual relations. All these structures do not exist in order subsequently, to enter into certain relationships; rather, it is these relations themselves which determine and completely exhaust the being expressed in mathematical concepts. Likewise concepts like atoms or electrons fully share the logical character of these geometrical concepts. They do not admit of an explicit definition but basically can only be defined implicitly. In this respect there is no difference between the material point and the ideal mathematical point. To such a point also no being in itself can be ascribed; it is constituted by a definite aggregate of relations, and consists in this aggregate. (DI, 195).

The contemporary structural realists French and Ladyman comment that this „structural dissolution of physical objects leads to a blurring of the line between the mathematical and the physical“ (French and Ladyman $(2003,41)$. This may well be true, but it certainly does not adequately express the full content of Cassirer's original sameness thesis. On the other hand, it should be noted that Cassirer does not contend that physical and mathematical concepts are identical:

The difference between mathematical and physical concepts consists solely in the way they are constituted: Mathematical concepts can be obtained by construction; we "create" these concepts by means of the conditions which we impose on them, by means of the systems of axioms which they have to satisfy. In physics the place of these logical axioms is taken by the hypothetical formulation of the basic concepts, and by hypothetical deductions. (DI, 195-196) 
At the end of DI we eventually have come full circle back to the point from which we have started: Clearly, these considerations just rehearse for quantum mechanics the „sameness thesis“ that Cassirer had put forward for classical physics already in KMM and SF, namely, that mathematical and empirical concepts are of the same kind. In other words, at the end of DI it becomes evident that Cassirer reads quantum theory as the strongest available confirmation of the fundamental thesis of his version of the Marburg Neo-Kantian philosophy of science according to which mathematical and empirical concepts spring from the same origin, namely, the conceptual activity of the mind.

From KMM through both SF and DI, Cassirer holds fast to the thesis of the conceptual sameness of mathematical and physical concepts. He even claimed that quantum mechanics further confirmed this contention. This basic methodological thesis of his "critical idealism“ survived all the revolutions that took place in the course of the physics of 20th century. By emphasizing the role of implicit definitions for physical concepts quantum mechanics confirms also for post-classical physics the close affinity between mathematical and empirical concepts. Thereby the basic thesis of Cassirer's philosophy of science, namely, that the formation of mathematical and physical concepts follows the same pattern, is validated also for post-classical physics.

5. On the Reception of Determinism and Indeterminism. When Cassirer published DI in 1937 the political and cultural circumstances were anything but favorable for the success of such a book. Cassirer had been exiled from Germany for four years and was living in Sweden. DI, although written in German, could not be published in any German-speaking country, but had to appear in a Swedish publishing house. Taking these negative factors into account, nevertheless, the book was rather successful in its original German version. 
In contrast to Cassirer's treatise on Einstein's relativity theory (ERT) some fifteen years prior, DI did not meet strong opposition from the camp of the logical empiricists. On the contrary, in a review of DI, Philipp Frank, one of the hardliners of logical empiricism, somewhat grudgingly felt obliged to admit that he essentially agreed with Cassirer's account of quantum mechanics (cf. Frank 1938). More precisely, he conceded that Cassirer's interpretation of quantum mechanics was fully in line with the logical empiricist interpretation of this theory that the members of the Vienna Circle had "always“ maintained. From Frank's perspective, DI was evidence that one of the leading representatives of "school philosophy“ was on his way toward a truly scientific world view. Needless to say, this interpretation did not fully coincide with that of Cassirer who, to repeat it again, considered quantum mechanics as another confirmation for the feasibility of his idealist relational philosophy of science.

In 1956, ten years after Cassirer death, an English translation of DI was released. In the preface of the English edition, Henry Margenau, Cassirer's colleague at Yale and one of the leading quantum physicists of the time, praised his work in enthusiastic terms as follows:

The book [DI] was ahead of its day; its thesis was revolutionary and radical, not, like so many philosophical commentaries, a wordy echo of the scientists' own pronouncements. For at a time when every physicist spoke of the uncertainty principle as a restrictive injunction on the process of measurement,... Cassirer saw more deeply and perceived a basic change in the meaning of reality. ... he showed that the causal controversy which raged at the time was not itself of crucial importance but was an outgrowth of a more fundamental issue (Cassirer $1956, x)$

Margenau, playing the role of Cassirer in his preface of $\mathrm{DI}$, describes as the main merit of this book the fact that it reminded the physicists of the following urgent issues on their agenda: 
Your interpretation of uncertainty is a halfway concession. You cannot continue to use the classical models in your reasoning and make your peace with the new doctrine by admitting errors of observation forever beyond human control. You must grant that the very concepts of „physical system“ and „physical state“ have changed. By going to this deeper level of analysis, you can retain what most philosophers have regarded as causal description. (DI, $\mathrm{x}$ )

Margenau even used the expression „prophetic“ with respect to DI. Meanwhile, much time has passed and Cassirer's „prophetic“ thesis that quantum particles should be considered, in some sense, not as individuals, has become the „received view“ (French and Rickles 2003, 221). Some physicists were convinced that this loss of individuality is something much more fundamental, and much more difficult to digest than the change from classical space and time to the relativistic space-time concept“. (ibid.)

.. [Cassirer's] view has stood the test of two decades and enjoys greater popularity today than when it was propounded. (DI x, xi):

Margenau's contention that Cassirer's interpretation of quantum mechanics was „ahead of its day" has been confirmed in an unexpected way much later. Cassirer is the only classical philosopher of science whom contemporary structuralist philosophers of quantum mechanics recognize as a precursor of the contemporary structuralist approach. This appropriation has, however, some paradoxical features. While Cassirer was at pains to present his philosophical interpretation of quantum mechanics as a confirmation and deepening of his Neo-Kantian Ansatz, the structuralists of the 21 th century try hard to play down the genuinely NeoKantian ingredients in Cassirer's thought that lead him to a structural interpretation of the new physics. 
Be this as it may, in the most recent version (2010) of the entry on "quantum mechanics“ in the Stanford Encyclopedia of Philosophy, which may be considered as an authoritative source for the general philosophical public, DI is mentioned as a classical work of philosophy of quantum mechanics. This may be taken as convincing evidence that Margenau was right with his assessment.

Nevertheless, the reception of $\mathrm{DI}$ in contemporary philosophy of science exhibits some almost paradoxical features. While quite a few philosophers of science with explicit antiKantian inclinations welcome Cassirer's explicitly Neo-Kantian contributions to the philosophy of quantum mechanics, in the camp of the avowed partisans of Neo-Neo-Kantian philosophy of science DI has been largely ignored. For instance, Michael Friedman, one of the leading exponents of this current, does not even mention DI once his Dynamics of Reason (Friedman 2001). Despite his high esteem for Cassirer's philosophy he contends that up to now the philosophy of science has not provided a philosophically sufficiently profound interpretation of quantum mechanics - in contrast to the other non-classical theory, i.e., relativity theory. For quantum mechanics we allegedly lack the means „to rationally bridge the gap between prerevolutionary and post-revolutionary conceptual landscapes“ (Friedman 2001, 120). As it seems, Friedman opines that DI was of no help in overcoming this shortcoming.

This pessimistic view is in stark contrast with Cassirer's own assessment of the state of the art. The later Cassirer argued in DI that the gap beween quantum and pre-quantum physics could be rationally bridged although many philosophers and scientists were inclined to deny this. It should be noted that Cassirer did not undertake lightly his strong „no-revolutionary thesis“. He was well aware of the fact that his thesis that his Neo-Kantian relational account scientific knowledge was able to overcome the apparent gap between classical and nonclassical physics did not find unanimous agreement. For instance, he was well aware of the fact that Planck, one of the founding fathers of the new theory, had characterized his „Quantenhypothese“ as a „dangerous explosive“ for classical physics, far more dangerous 
than Einstein's theories. In sum, the Rezeptionsgeschichte of DI is anything but simple and univocal and remains an interesting task for the history of the philosophy of science.

6. A Structural Realist avant la lettre? $D I$ is recognized as an important early work in the philosophy of quantum mechanics. In light of contemporary discussions, one may say with only a bit of exaggeration that Cassirer has had an impressive posthumous career as a structuralist philosopher of quantum physics. Quite a few contemporary philosophers of quantum theory have proposed considering Cassirer as an early representative of a structuralist philosophy of science (cf. French and Ladyman (2003), Ladyman and Ross (2007), Cei and French (2009), French (2014)). These authors propose considering Cassirer's approach as closely related to the so-called „ontological structural realism“ (OSR). In contemporary philosophy of science, in particular in the philosophy of quantum mechanics, one finds a bewildering profusion of "structuralisms". One of the most prominent is „structural realisms“ (SR). ${ }^{10}$

In this section l'd like to deal first with one member of SR, namely, the „ontological structural realism“ (OSR) of French, Ladyman, and others. These authors have come to recognize Cassirer as a precursor of this subspecies of structural realism. In the second half of this section I'll tentatively argue that Cassirer's idealist structuralism may have affinities not so much with some version of SR, but rather with another species of structuralism, namely, the one which van Fraassen has characterized as „empiricist structuralism“ (ES) (cf. van Fraassen 2006, 2008).

Let us start with a rough and informal sketch of OSR (cf. French 2014, Ladyman and Ross (2007, Frigg and Votsis 2011). In first approximation, OSR may be characterized by assertions such as „Only (relational) structures are real“, or, a bit more cautiously, „There

${ }^{10}$ Frigg and Votsis list no less than six subspecies XSR of structural realism SR (Frigg and Votsis 2011, 238). 
are relations in which the relation is primary, while the things are secondary." (Ladyman 2007,152 ), or „There are only relations and no relata“ (French 2014).

For Ladyman and French „the claim that relata are constructed as abstractions from relations“ does not imply that there are no relata; „rather the opposite“(!). This somewhat enigmatic contention is explained as follows:

A core aspect of the claim that relations are logically prior to relata is that the relata of a given relation always turn out to be relational structures themselves on further analysis (Ross/Ladyman 2007, 154/155).

In other words, OSR contends that, in one way or other, all the way down there are only relations. How can this bold thesis be reconciled with the fact that most people consider it as impossible to think of a relation without relata? Among the various proposals to overcome this difficulty one finds the following ingenious proposal of Ross and Ladyman:

Speculating cautiously about psychology, it is possible that dividing a domain up into objects is the only way we can think about it. ... We may not be able to think about structure without hypostatizing individuals as the bearers of structure, but it does not follow that the latter are ontologically fundamental. (Ladyman and Ross 2007, 155).

Whether Ladyman and Ross's "cautious psychological speculation“ is compelling, it is certainly not new. Almost one hundred years ago one finds it as an essential ingredient of an elaborated Neo-Kantian epistemology in SF that aims to elucidate the complex relation between objects and objectivity:

... we do not know „objects“, - as if they were already independently determined and given as objects, - but we know objectively, by producing certain limitations and by fixating certain permanent elements and connections within the uniform 
flow of experience. The concept of object in this sense constitutes no ultimate limit of knowledge, but is rather its fundamental instrument, by which all that has become its permanent possession is expressed and established. (SF, 303) AND (DI, 137)

Indeed, the distinction between "knowing objects“ and "objective knowledge“ was the cornerstone of Marburg Neo-Kantianism namely, the primacy of an objective scientific method over allegedly "real“ objects that exist "out there“. Cassirer considered this distinction as essential for the critical idealist approach überhaupt, as is evidenced by the extensive self-quotation concerning of the pertinent passage in DI taken from SF. Moreover, this link between DI and SF provides unmistakable evidence that DI is to be considered as a continuation of his earlier work.

Although the partisans of OSR are readily prepared to give a place of honor to Cassirer in the „prehistory of structuralism“ they shy away from close conceptual contact with his NeoKantian philosophy of science. For instance, in the section What we can take from Cassirer in (French 2014), Cassirer's legacy is summarized succinctly in the following general insights (French 2014, 99ff):

- Relations are conceptually prior to objects.

- The locus of objectivity shifts from objects to laws and symmetries.

In Cei and French $(2009,114)$ these two contentions are contextualized as consequences of the following three theses that encapsulate the allegedly neutral, non-Neo-Kantian essence of Cassirer's philosophy of science (cf. (DI, 35):

- Holism. Cassirer distinguishes between three different types of statements of statements in physics: statement of the results of measurement, statement of laws, and statements of principles ( $\mathrm{DI}$, chapter 3 ). 
- Functional coordination. All the statements of physics are determined through one another, the mutually condition and support one another, and their specific "truth“ is due precisely to this mutual interconnection. This reciprocal interweaving and bonding constitutes one of the basic features of the system of physics. There is only a functional coordination in which all the elements ... uniformally participate. (See (DI, 35)

- Centrality of the notion of Law. The laws are the features that in the theoretical setup bring about the coordinative component. They express the pattern that we then find instantiated in the various singular cases. In this sense the principles just replicate this coordinate "move“ at the more general level of the laws themselves. (Cei and French $(2009,113)$

Cei and French explicitly state that they do not want to suggest that "the debate on structuralism should move in a Neo-Kantian direction“ (ibid.). Rather, Cassirer's work is said to present elements of interest in a more general sense for the sagenda of structuralism. ${ }^{11}$ According to them, Cassirer's conclusions about quantum mechanics are not consequences of his Neo-Kantianism. All that is needed to conclude that quantum objects are not individuals are the just mentioned ingredients holism, functional coordination, and the centrality of the notion of law. (cf. Cei \& French (ibid., 114)).

This thesis is at variance with Cassirer's own interpretation of DI, according to which DI was a continuation and clarification of the account of scientific knowledge that he had formulated for classical physics some 25 years ago in SF (cf. DI, xxiii). In particular, the ingredients of holism, functional coordination, and the centrality of law already appear in SF. It seems, however, difficult to deny that SF is a genuine Neo-Kantian work.

\footnotetext{
${ }^{11}$ Rather vaguely, they adumbrate that Cassirer could teach contemporary philosophy of science that the concept of law of nature should play a major role in the debate on structuralism (cf. Cei and French (2009, 114), French $(2014, X X X)$. Be this as it may, a realization of this project presupposes that Cassirer's Neo-Kantian concept of law could be reformulated in an appropriate Non-Neo-Kantian way.
} 
Some further remarks on the relation of Cassirer's acount and the OSR-interpretation of it are in order. With respect to Cassirer's holism one may note that, in DI, he insisted on the importance of three types of statements of physical knowledge, namely, statements of the results of measurements, statements of laws, and statements of principles (cf. (DI, 35)). Cassirer's expression of a „reciprocal interweaving and bonding“ (DI) is taken up several times in French (2014) and Cei and French (2009) as evidence of the close affinity between Cassirer's and their account of structuralism. Neventheless a certain change of meaning seems to have taken place surreptiously. While Cassirer insisted on the holistic character of physical knowledge that comprised all three types of physical statements, Cei and French show a tendency toward a two-tiered approach that only recognizes laws and principles as generators of the entire system of physical knowledge:

The putative objects of the theory emerge from the interplay of the laws and the principles of the theory itself because they encapsulate the kind of constant patterns that ties together the empirical features that in different ways we consider to be properties of the object or consequences of the dynamics that the theory ascribes to its objects. In this sense, a working theory "generates" its own objects, and objectivity is grounded in the universality of laws and principles. (French $(2014,99)$.

Cei and French's claim that the objects of a theory emerge from the „interplay of the laws and the principles of the theory" is at variance with Cassirer's more thoroughgoing holism. Cassirer insists on the indispensible role of measurement statements (cf. DI, 35). If we characterize "laws“ and „principles“ as more idealized ingredients in a theory (in a sense that should be further specified, of course) one may say that the contemporary ontological structural realism subscribes to a more radical, eliminative structuralism that aims to eliminate objects completely. 
Finally one should observe that Cassirer's structuralism is more comprehensive. While the contemporary structural realists rely on quantum physics as principal evidence for the structuralist character of scientific knowledge, Cassirer's structuralism considers quantum physics only as one among many arguments for a structuralist interpretation of physical knowledge. For Cassirer, quantum theory is only the most recent, although perhaps the most powerful argument for the structural character of scientific knowledge. Cassirer not only asserts that quantum objects are relationally defined non-individuals, but quite generally that classical and non-classical (quantum) physics are relational knowledge.

From the perspective of Cassirer's "critical idealism" the structural realism of OSR amounts to a version of idealism in du Bois-Reymond's sense, which Cassirer had critizised as overstated and distorted already in SF. Thus one may doubt, whether Cassirer's moderate idealist structuralism really is compatible with (OSR).

Fortunately, structural realism is not the only game in town. There are also other structuralisms available. In the rest of this section l'd like to deal tentatively with Van Fraassen's Empiricist Structuralism (ES). For van Fraassen, the motivation for giving ES a try in Scientific Representation (van Fraassen 2008) is similar to that of Cassirer in SF and subsequent works, namely, to make sense of mathematization as one of the characteristic tendencies of modern science.

Van Fraassen opens the chapter on ES with the thesis that one of the major tasks of the philosophy of modern science is to make sense of "the mathematization of the (scientific) world-picture that culminated in the twentieth century“ (van Fraassen 2008, 237). As he rightly points out, this transition incites the philosophy of science to develop views of science that help justify and explain the ever growing impact of mathematics on the sciences. Although the various structuralist attempts in the history of the philosophy of science cannot be said to have coped with this task in a fully satisfying way, van Fraassen is convinced that there is still hope to set up a version of structuralism that really works. Not 
surprisingly, he is convinced that only a structuralism in an empiricist setting will do. (van Fraassen 2008, 238). ES is defined as follows (van Fraassen 2007, 238). Essential to an empiricist structuralism is the following core construal of the slogan that all we know is structure:

- Science represents the empirical phenomena as embeddable in certain abstract structures (theoretical models).

- Those abstract structures are describable only up to structural isomorphism. ${ }^{12}$

Since The Scientific Image (van Fraassen 1980) the concept of „embedding empirical phenomena in abstract structures" has been one of the most interesting and difficult concepts of van Fraassen's constructive empiricism. What exactly does it mean that empirical structures can be embedded (or represented) as substructures of more complex structures that include theoretical ingredients? I think that the idea of such an „embedding“ is sufficiently flexible to allow different interpretations. In the rest of this section I propose to interpret it in a way that is suggested by Cassirer's relational account of physical knowledge, namely, the embedding of empirical phenomena corresponds to the replacement of empirical concepts by idealized or limiting concepts. For instance, physical space is replaced by homogeneous and isotropic mathematical space, physical bodies are replaced by their mathematical models, etc. The crucial point here is that according to van Fraassen's "constructive empiricism“ as well as to Cassirer's "critical idealism" there is no need to ascribe to the embedding structure a reality that renders them structural entities "out there“. As Cassirer put it:

\footnotetext{
12 The abstract character of these structures, i.e., the fact that they can be described only „up to structural isomorphism" evidences that it is not important what these structures "are“", but what they are good for, i.e., what is their functional role. This is quite in line with Cassirer's conception of ideal concepts.
} 
Also the ideal concepts of natural science affirm nothing regarding a new realm of separate absolute objects, but they would only establish the inevitable, logical lines of direction, by which alone complete orientation is gained within the manifold of phenomena. They only go beyond the given, in order to grasp the more sharply the systematic structural relations of the given. (SF, 128).

The only "reality" that one can claim for them is their "objectivity" in the sense that they achieve their purpose, namely, to order the phenomena in an ever more comprehensive and perspicuous manner. But, as Cassirer pointed out already in SF "reality“ and "objectivity“ should not be confused (see section 3).

This kind of flexible empiricism concerning the role of the theoretical (idealizing) ingredients of a theory such as laws and principles, seems more in line with Cassirer's modest idealism than the rather robustly realist assumptions of OSR. Thus, tentatively, l'd like to conclude that ES may be more congenial to Cassirer's idealist structuralism than OSR.

To be sure, these two sketches of possible affinities between Neo-Kantian structuralism and and contemporary versions of structuralism such as ORS and ES in no way claim to have settled the issue of determining definitively Cassirer's place in the landscape of the many versions of structuralism presently available. Their only purpose was to show that this problem is still an unsolved and interesting problem in history of philosophy of science.

Im sum, the project of the partisans of OSR to „bring Cassirer's philosophy of quantum mechanics into the twenty-first century“ by eliminating its Neo-Kantian content of the twentieth century looks a bit quixotic, to say the least.

\section{References:}

Bueno, O., French, S., Ladyman, J., 2002, On Representing the Relationship between the Mathematical and the Empirical, Philosophy of Science 69, $452-73$. 
Cartwright, N., 1999, The Dappled World. A Study of the Boundaries of Science, Cambridge, Cambridge University Press.

Cassirer, E., 1902(1998), Leibniz' System in seinen wissenschaftlichen Grundlagen, Hamburg, Felix Meiner Verlag.

Cassirer, E., 1907, Kant und die moderne Mathematik, Kantstudien 12, 1 - 49.

Cassirer, E., 1910, Substanzbegriff und Funktionsbegriff, Darmstadt, Wissenschaftliche Buchgesellschaft. English translation in Substance and Function and Einstein's Theory of Relativity, Chicago and LaSalle, Open Court, 1923.

Cassirer, E., 1921, Zur Einsteinschen Relativitätstheorie, Darmstadt, Wissenschaftliche Buchgesellschaft, English translation in Substance and Function and Einstein's Theory of Relativity, Chicago and LaSalle, Open Court, 1923.

Cassirer, E., 1937, Determinismus und Indeterminismus in der modernen Physik; historische und systematische Studien zum Kausalproblem, Göteborg, Elanders Boktryckeri Aktiebolag. English Translation published as Determinism and Indeterminism in Modern Physics. Historical and Systematic Studies 1956 by Yale University Press, New Haven.

Cei, A., French, S., 2009, On the Transposition of the Substantial into the Functional: Bringing Cassirer's Philosophy of Quantum Mechanics into the 21 st Century, in M. Bitbol, P. Kerszberg, and J. Petitot (eds.), Constituting Objectivity, Transcendental Perspectives on Modern Phy-sics, The Western Ontario Series in Philosophy of Science, Dordrecht, Springer, 95- 115.

Frank, P., 1938(1949), Determinism and Indeterminism in Modern Physics, (Review of Cas-sirer 1937), in Philipp Frank, Modern Science and its Philosophy, Cambridge/Massachu-setts, Harvard University Press, 172 - 185.

French, S., Ladyman, J., 2003, Remodelling Structural Realism: Quantum Mechanicss and the Metaphysics of Structure, Synthese 136, 31 - 56.

French, S., 2014, The Structure of the World, Oxford, Oxford University Press. 
Friedman, M., 2001, The Dynamics of Reason, Stanford, CSLI Publications.

Frigg, R., Votsis, I., 2011, Everything you always wanted to know about structural realism but were afraid to ask, European Journal of Philosophy of Science 1, $227-276$.

Ihmig, K.-N., 1999, Ernst Cassirer and the Structural Conception of Objects in Modern Science: The Importance of the „Erlanger Program“, Science in Context 12, 513 - 29.

Ihmig, K.-N., 2001, Grundzüge einer Philosophie der Wissenschaften bei Ernst Cassirer, Darmstadt, Wissenschaftliche Buchgesellschaft.

Ladyman, J., Ross, D., 2007, Every Thing Must Go. Metaphysics Naturalized, Oxford University Press, Oxford.

Margenau, H., 1935, Methodology of Modern Physics, 2 parts, Philosophy of Science 2, 48 72 and $164-178$.

Margenau, H., 1950, The Nature of Physical Reality: A Philosophy of Modern Physics, New York, McGraw Hill.

Nagel, T., 1961, The Structure of Science: Problems in the Logic of Scientific Explanation, New York, Harcourt, Brace, and World.

Natorp, P., 1910, Die logischen Grundlagen der exakten Wissenschaften, Leipzig und Berlin, Teubner.

Norton, J., 2007, Causation as Folk Science, in H. Price and R. Corry (eds.) Causation, Physics and the Constitution of Reality, Oxford, Oxford University Press, 11 - 44.

van Fraassen, B.C., 2006, Structure: its substance and shadow, British Journal for the Philosophy of Science 57, $275-307$.

van Fraassen, B.C., 2006a, Representation: the Problem for Structuralism, Philosophy of Science 74, $536-547$.

van Fraassen, B.C., 2008, Scientific Representation, Oxford, Oxford University Press. du Bois-Reymond, E., 1872, Über die Grenzen des Naturerkennens, in Emil du Bois-Reymond, Vorträge über Philosophie und Gesellschaft, Hamburg, Meiner, 1974. 
du Bois-Reymond, P., 1882, Die Allgemeine Functionentheorie, Erster Teil, Tübingen, Verlag der H. Laupp'schen Buchhandlung.

du Bois-Reymond, P., 1890, Über die Grundlagen der Erkenntnis in den exacten Wissenschaften, Verlag der Laupp'schen Buchhandlung, Tübingen.

Ryckman, T., 1991, Conditio sine qua non? Zuordnung in the early epistemologies of Cassirer and Schlick, Synthese 88, 57 - 95.

Ryckman, T., 2005, The Reign of Relativity. Philosophy in Physics 1915 - 1925, Oxford, Oxford University Press.

Schlick, M., 1921, Kritizistische oder empiristische Deutung der neuen Physik?, Kant-Studien 26, Heft $1-2,96-111$.

Schlick, M., $1925^{2}$ (2009), Allgemeine Erkenntnislehre, Springer. English Translation as General Theory of Knowledge, Chicago and La Salle, Open Court, 1985.

Schlick, M., 1931 (1961), Causality in Contemporary Physics, British Journal for the Philosophy of Science 12, $177-193$.

Stamatescu, I.O., 1997, Cassirer und die Quantenmechanik, in E. Rudolph und I.O. Stamatescu (Hrg.) Vor der Philosophie zur Wissenschaft. Cassirers Dialog mit der Naturwissenschaft, Hamburg, Meiner, $17-35$.

Stöltzner, M., 2009, The Logical Empiricists, in H. Beebee, C. Hitchcock, P. Menzies (eds.), The Oxford Handbook of Causation, Oxford, Oxford University Press, 108 - 127.

Torretti, R., 1999, The Philosophy of Physics, Cambridge, Cambridge University Press.

Weyl, H., 1927(1980), Philosophie der Mathematik und Naturwissenschaft, Oldenbourg, München. 